\title{
Exergy Analysis of Organic Rankine Cycle with Internal Heat Exchanger
}

\author{
Kyoung Hoon Kim, Hyung Jong Ko, and Se Woong Kim
}

\begin{abstract}
In recent years Organic Rankine Cycle (ORC) has become a field of intense research and appears a promising technology for conversion of heat into useful work or electricity. In this work thermodynamic performance of ORC with internal heat exchanger is comparatively assessed for various working fluids based on the second law of thermodynamics. Special attention is paid to the effect of turbine inlet pressure on the exergy destructions (anergies) at various system components and the exergy efficiency of system. Results show that for a given source the component at which the greatest anergy occurs differs with working fluid. As turbine inlet pressure increases, exergy efficiency increases for working fluid such as ammonia or R22, but decreases for working fluid with low critical pressure such as iso-pentane or n-pentane.
\end{abstract}

Index Terms-Organic rankine cycle (ORC), internal heat exchanger, exergy, anergy.

\section{INTRODUCTION}

Statistical investigations indicate that the low-grade waste heat accounts for $50 \%$ or more of the total heat generated in industry. Due to the lack of efficient recovery methods, a lot of the low-grade energy is merely discarded. Since the worldwide energy demand has been rapidly increasing but the fossil fuel to meet the demand is being drained, an efficient use of the low-temperature energy source such as geothermal energy, exhaust gas from gas turbine system, biomass combustion, or waste heat from various industrial processes becomes more and more important. ORC is a Rankine cycle where an organic fluid is used instead of water as working fluid and appears as a promising technology for conversion of low-grade heat into useful work or electricity, since it exhibits great flexibility, high safety and low maintenance requirements [1]-[2]. In an ORC the saturation vapor curve is the most crucial characteristics of a working fluid. This characteristic affects the fluid applicability, cycle efficiency, and arrangement of associated equipment in a power generation system [3].

Drescher and Bruggemann [4] investigate the ORC in solid biomass power and heat plants, and they propose a method to find suitable thermodynamic fluids for ORCs in biomass plants. They assert that the family of alkylbenzenes show the highest efficiency. Dai et al [5] use a generic optimization algorithm identifying isobutane and R236ea as efficient working fluids. Heberle and Brueggemann [6] investigate the combined heat and power generation for geothermal

Manuscript received December 5, 2012; revised February 6, 2013.

The authors are with the Department of Mechanical Engineering, Kumoh National Institute of Technology, Gumi, Gyeongbuk 730-701, Korea (e-mail: $\{$ khkim, kohj, ksw\}@ kumoh.ac.kr). resources with series and parallel circuits of an ORC.

Tranche et al. [7] investigate comparatively the performance of solar organic Rankine cycle using various working fluids. Volume flow rate, mass flow rate and power ratio as well as thermal efficiency are used for comparison. Hung et al. [8] examine Rankine cycles using organic fluids which are categorized into three groups of wet, dry and isentropic fluids. They point out that dry fluids have disadvantages of reduction of net work due to superheated vapor at turbine exit, and wet fluids of the moisture content at turbine inlet, so isentropic fluids are to be preferred.

Kim [9], [10] examines comparatively the thermodynamic performance of ORC with superheater or internal heat exchanger for various working fluids including wet, dry and isentropic fluids. He points out that in selection of working fluid it is required to consider various criteria of performance characteristics as well as thermal efficiency. Kim and Han [11] investigate the thermodynamic performance of transcritical ORC with and without internal heat exchanger for various working fluids. They point out that operation with supercritical cycles can provide better performance than that of subcritical cycles because of better thermal match between the working fluid and the sensible heat source. Kim and Ko [12] carry out exergy performance assessment of ORC with superheating comparatively for various organic fluids. They show that for a given source both the anergies and exergy efficiency may have a peak value or monotonically increase with evaporating temperature.

In this paper, the thermodynamic exergetical performance of the organic Rakine cycle with internal heat exchanger is comparatively and parametrically investigated based on the second law of thermodynamics for various working fluids. The exergy destructions (anergies) at various components in ORC including source exchanger, exhaust, condenser, and internal exchanger, as well as exergy efficiency are investigated in terms of the system parameters such as turbine inlet pressure.

\section{SYSTEM ANALYSIS}

The schematic diagram of the system is shown in Fig. 1. The system considered in this work consists of condenser, pump, turbine, regenerator, preheater, boiler, and superheater. A low-grade energy in the form of sensible energy is supplied to the system. The working fluids considered in this work are nine fluids of $\mathrm{NH}_{3}$ (ammonia), R134a, R22, $\mathrm{iC}_{4} \mathrm{H}_{10}$ (iso-butane), R152, R143a, $\mathrm{C}_{4} \mathrm{H}_{10} \quad$ (butane), $\mathrm{iC}_{5} \mathrm{H}_{12}$ (iso-pentane), $\mathrm{nC}_{5} \mathrm{H}_{12}$ (normal pentane). The thermodynamic properties of the working fluids are calculated by Patel-Teja equation of state [12], [13]. 


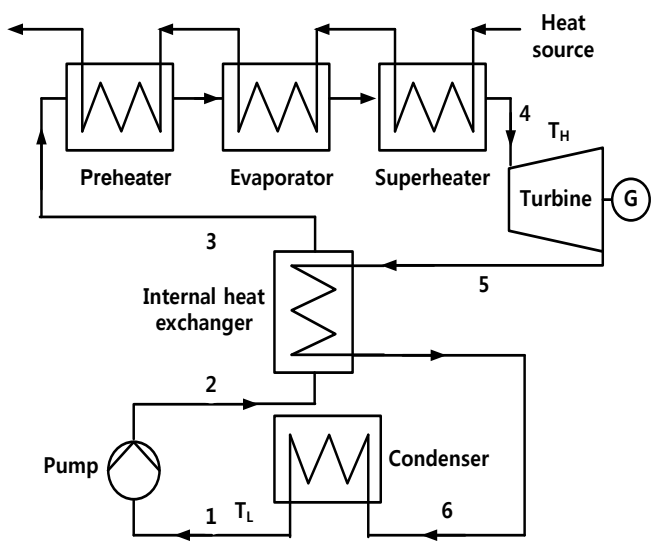

Fig. 1. Schematic diagram of the system.

$$
\begin{gathered}
P=\frac{R T}{v-b}-\frac{a(T)}{v(v+b)+c(v-b)} \\
a(T)=\Omega_{a}\left(\frac{R^{2} T_{c}^{2}}{P_{c}}\right) \alpha(T) \\
b=\Omega_{b}\left(\frac{R T_{c}}{P_{c}}\right) \\
c=\Omega_{c}\left(\frac{R T_{c}}{P_{c}}\right)
\end{gathered}
$$

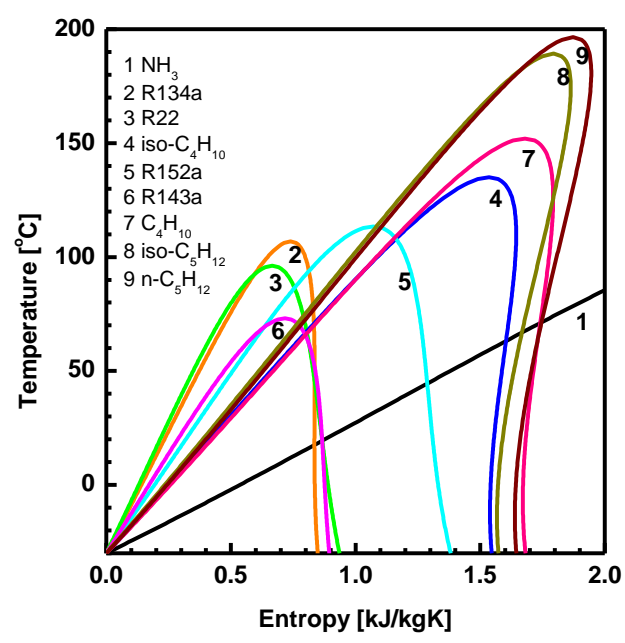

Fig. 2. Temperature-entropy diagrams of working fluids.

The basic data of the fluids which are needed to calculate Patel-Teja equation are shown in TABLE I, where $M, T_{\mathrm{c}}, P_{\mathrm{c}}$ and $\omega$ are molecular weight, critical temperature, critical pressure, and accentric factor, respectively [14]. The molecular weights of $\mathrm{NH}_{3}$ and $\mathrm{iC}_{4} \mathrm{H}_{10}$ are small, and those of R123 and $\mathrm{C}_{8} \mathrm{H}_{12}$ are large among the fluids. The critical temperatures of R143a and $\mathrm{R} 22$ are low and those of $\mathrm{nC}_{5} \mathrm{H}_{12}$ and $\mathrm{iC}_{5} \mathrm{H}_{12}$ are high. The critical pressures of $\mathrm{nC}_{5} \mathrm{H}_{12}$ and $\mathrm{iC}_{5} \mathrm{H}_{12}$ are low and those of $\mathrm{NH}_{3}$ and $\mathrm{R} 22$ are high. The temperature-entropy diagrams for the fluids are shown in Fig. 2. It can be seen from the figure that $\mathrm{iC}_{4} \mathrm{H}_{10}, \mathrm{C}_{4} \mathrm{H}_{10}, \mathrm{iC}_{5} \mathrm{H}_{12}$ and $\mathrm{nC}_{5} \mathrm{H}_{12}$ belong to dry fluids, $\mathrm{R} 134 \mathrm{a}$ and $\mathrm{R} 143 \mathrm{a}$ to isentropic fluids, and $\mathrm{NH}_{3}, \mathrm{R} 22$ and $\mathrm{R} 152 \mathrm{a}$ to wet fluids. Especially, the latent heat of vaporization of $\mathrm{NH}_{3}$ is much greater than the others so the whole temperature-entropy diagram for $\mathrm{NH}_{3}$ is not shown in the figure [12].

TABLE I: BASIC DATA FOR THE WORKING FLUIDS

\begin{tabular}{crrrc}
\hline \hline Substance & $\mathrm{M}(\mathrm{kg} / \mathrm{kmol})$ & $\mathrm{T}_{\mathrm{c}}(\mathrm{K})$ & $\mathrm{P}_{\mathrm{c}}(\mathrm{bar})$ & $\omega$ \\
\hline $\mathrm{NH} 3$ & 17.031 & 405.65 & 112.78 & 0.252 \\
\hline $\mathrm{R} 134 \mathrm{a}$ & 102.031 & 380.00 & 36.90 & 0.239 \\
\hline $\mathrm{R} 22$ & 86.468 & 369.30 & 49.71 & 0.219 \\
\hline $\mathrm{iC}{ }_{4} \mathrm{H}_{10}$ & 58.123 & 408.14 & 36.48 & 0.177 \\
\hline $\mathrm{R} 152 \mathrm{a}$ & 66.051 & 386.60 & 44.99 & 0.263 \\
\hline $\mathrm{R} 143 \mathrm{a}$ & 84.041 & 346.25 & 37.58 & 0.253 \\
\hline $\mathrm{C}_{4} \mathrm{H}_{10}$ & 58.123 & 425.18 & 37.97 & 0.199 \\
\hline $\mathrm{iC}_{5} \mathrm{H}_{12}$ & 72.150 & 460.43 & 33.81 & 0.228 \\
\hline $\mathrm{nC}_{5} \mathrm{H}_{12}$ & 72.150 & 469.65 & 33.69 & 0.249 \\
\hline \hline
\end{tabular}

A low-grade sensible energy is supplied to the system and important assumptions used in this work are as follows. 1) The energy source is air at temperature of $T_{S}$. 2) The working fluid leaves the condenser as saturated liquid at temperature of $T_{L} .3$ ) The evaporating temperature, $T_{E}$ is lower than the critical temperature of the fluid and the turbine inlet temperate becomes $T_{S}-\Delta T_{H}$ by the superheater. 4) The minimum temperature difference between the hot and cold streams in the regenerator is operated at a prescribed pinch point, $\left.\Delta T_{P P} .5\right)$ Pressure drop and heat loss of the system are negligible.

At point 1 , the fluid is saturated liquid at $T_{L}$ and the corresponding saturated pressure $P_{L}$ is the low pressure of the system. When the turbine inlet pressure is $P_{H}$, the corresponding saturation temperature $T_{E}$ is the evaporation temperature of the system. The thermodynamic properties at point 4 are determined with the temperature $T_{H}$ and the pressure $P_{H}$. The thermodynamic properties at points 2 and 5 are determined with the isentropic efficiencies of pump and turbine, $\eta_{p}$ and $\eta_{t}$, respectively.

As the mass flow rate of working fluid for a given energy source increases, the temperature of source flow at preheater exit decreases, and finally the temperature difference between the source and the working fluid reaches the pinch point value $\Delta T_{\mathrm{PP}}$ when the mass flow rate of working fluid is increased to its maximum value. Then the ratio of mass flow rate of a working fluid to that of the source, $r_{m}$, can be determined as

$$
\begin{gathered}
r_{m}=\frac{\dot{m}_{w f}}{\dot{m}_{s}}=\frac{c_{p s}\left(T_{s}-T_{s, \text { out }}\right)}{h_{4}-h_{3}} \\
T_{s, \text { out }}=T_{3}+\Delta T_{P P}
\end{gathered}
$$

where subscripts $w f$ and $s$ denote the working fluid and the source fluid, respectively, and $\dot{m}$ the mass flow rate, $T$ the temperature, $h$ the specific enthalpy, $c_{p s}$ the constant pressure specific heat of source fluid, and $\Delta T_{\mathrm{PP}}$ the pinch point temperature difference of the heat exchanger.

The rate of heat input and net work are obtained as

$$
\begin{gathered}
\dot{Q}_{i n}=\dot{m}_{w f}\left(h_{4}-h_{3}\right) \\
\dot{W}_{n e t}=\dot{W}_{t}-\dot{W}_{p}=\dot{m}_{w f}\left[\left(h_{4}-h_{5}\right)-\left(h_{2}-h_{1}\right)\right]
\end{gathered}
$$


where subscripts $t$ and $p$ denote turbine and pump, respectively [10].

When a system undergoes a steady state operation, the thermodynamic properties of working fluid can be arbitrarily assigned to be zero as reference values. Therefore the thermo-mechanical enthalpy, entropy, and exergy at the ambient condition or dead state can be neglected regardless of its chemical composition. The specific exergy $e$ and the rate of exergy input to the system by source fluid can be calculated as [12]

$$
\begin{gathered}
e=h-h_{0}-T_{0}\left(s-s_{0}\right) \\
\dot{E}_{\text {in }}=\dot{m}_{s} c_{p s}\left\{T_{s}-T_{0}-T_{0} \ln \left(T_{s} / T_{0}\right)\right\}
\end{gathered}
$$

where $s$ is the specific entropy and subscript 0 means the dead state. The exergy efficiency of the system $\eta_{e x}$, which is defined as the ratio of net work to exergy input, can be written as follows.

$$
\eta_{e x}=\dot{W}_{n e t} / \dot{E}_{i n}
$$

The exergy destruction or anergy of the adiabatic system is calculated as the difference of exergy input and output. The anergy ratio at the system component such as preheater is defined as the ratio of anergy there to exergy input by source fluid.

\section{RESULTS AND DISCUSSIONS}

In this work the basic data for analysis are $T_{L}=20^{\circ} \mathrm{C}, T_{S}=$ $200^{\circ} \mathrm{C}$ and $\Delta T_{H}=15^{\circ} \mathrm{C}$, so the turbine inlet temperature in this work is fixed at $T_{H}=T_{S}-\Delta T_{H}=185^{\circ} \mathrm{C}$. The turbine inlet pressure $P_{H}$ is varied from 20 to 50 bar under the restriction that $P_{H}$ is lower than the critical pressure of the working fluid and the minimum temperature difference between the streams in the heat exchangers is equal to the prescribed pinch point temperature difference, $\Delta T_{\mathrm{PP}}$. Since the cycle performance is strongly dependent on the source temperature level, the exergetical performance of ORC with superheating is assessed by investigating the dependence of anergy ratio (Figs. 3 6) and exergy efficiency (Fig. 7) on the turbine inlet pressure.

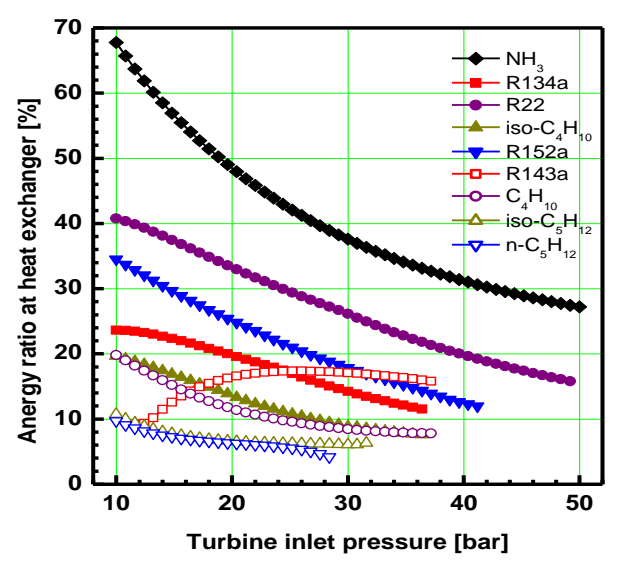

Fig. 3. Anergy ratio at heat exchanger.

Fig. 3 shows the effects of turbine inlet pressure on the anergy ratio at source heat exchanger for various working fluids. Because of the limitation of turbine inlet pressure lower than the critical pressure, the range of the turbine inlet pressure is narrower for some fluids such as iso-pentane or normal pentane. The anergy ratio at heat exchanger decreases monotonically with increasing turbine inlet pressure except for the case of R143a whose critical temperature is the lowest, at least for the specified condition of the work. For a specified value of the turbine inlet pressure, the anergy ratio for ammonia or R22 which has high critical pressure is high, while that of iso-pentane or normal pentane which has low critical pressure is low. For ammonia, the anergy ratio at heat exchanger is the greatest among the components of the system.

The anergy ratios at internal heat exchanger or regenerator are plotted with respect to turbine inlet pressure in Fig. 4 for each fluid. The anergy ratio is a monotonically decreasing function of turbine inlet pressure for all fluids. This is mainly because as the turbine inlet pressure increases, the turbine exit temperature decreases due to higher pressure ratio, and it leads smaller temperature difference of the hot and cold streams inside the internal heat exchanger. For a specified value of the turbine inlet pressure, the anergy ratio for R143a or R22 is high, while that of iso-pentane or normal pentane which has low critical pressure is low. For R143a, the anergy ratio at regenerator is the greatest among the components of the system.

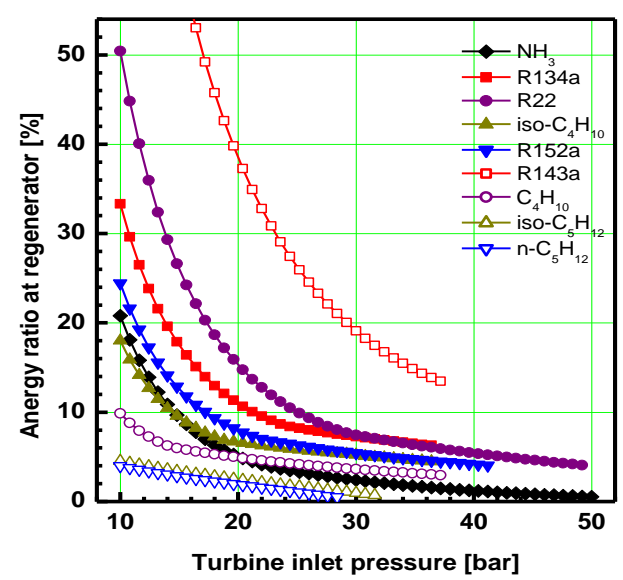

Fig. 4. Anergy ratio at regenerator.

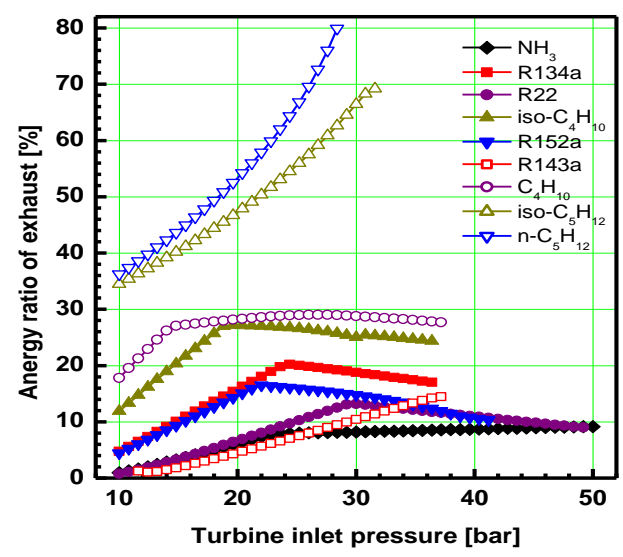

Fig. 5. Anergy ratio of exhaust.

Fig. 5 shows the effect of turbine inlet pressure on the 
anergy ratio due to exhaust of source fluid for the working fluids. As turbine inlet pressure increases, the anergy ratio increases at a certain rate, and after a certain point its increasing rate becomes lower. This can be explained as follows. As the turbine inlet pressure increases, the corresponding saturated temperature also increases, which causes the exit temperature of source fluid higher. Then, the temperature difference between fluid streams increases in the heat exchanger, so exergy destruction does. However, when the turbine inlet pressure increases to a certain value at which the working fluid entering the heat exchanger as saturated liquid, the increasing rate of exit temperature of source fluid becomes smaller or even minus. For a specified value of the turbine inlet pressure, the anergy ratio for iso-pentane or normal pentane is high, but that of R143a or ammonia is relatively low. The anergy ratio due to exhaust of source fluid is the greatest among the components of the system.

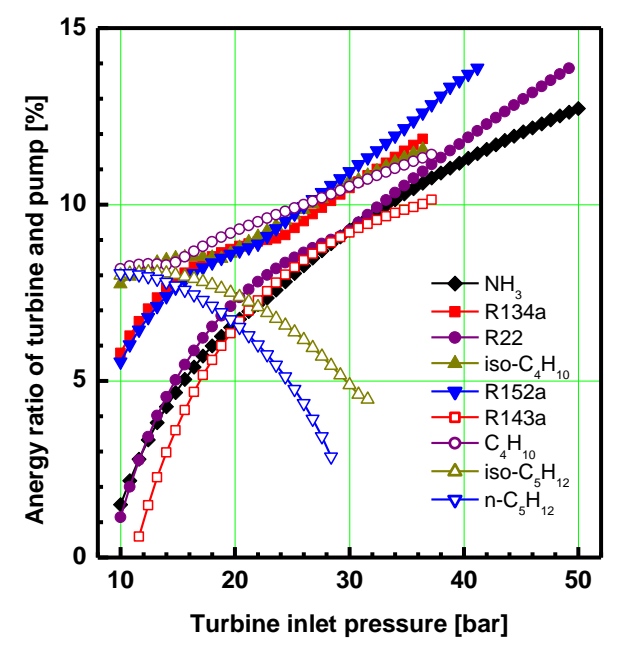

Fig. 6. Anergy ratio of turbine and pump

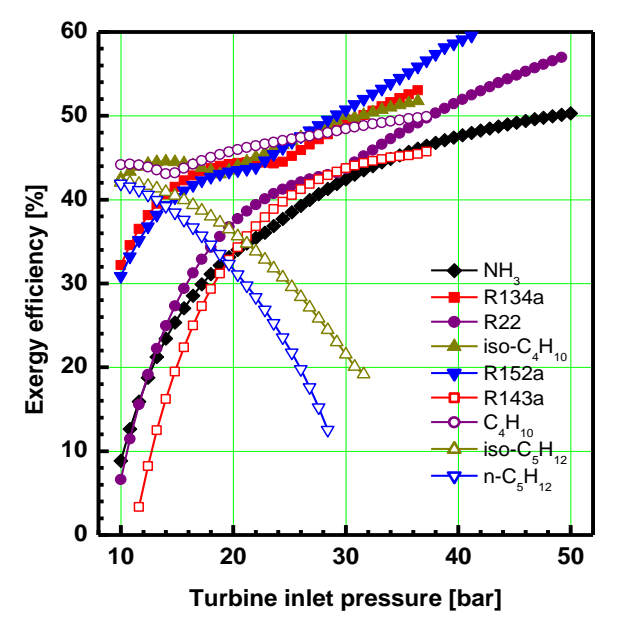

Fig. 7. Exergy efficiency

For various working fluids, Fig. 6 and Fig. 7 show the effect of turbine inlet pressure on the anergy ratio of turbine/pump and exergy efficiency, respectively. As it is seen in the figures, the anergy ratio of mechanical work of turbine and pump is approximately proportional to the exergy efficiency, since in this work isentropic efficiencies of turbine and pump are assumed to be constant for various values of system parameters. The increase in the turbine inlet pressure has positive or negative effect on the exergy efficiency, which is dependent on the working fluid. As turbine inlet pressure increases, the exergy efficiency increases for ammonia, R134a, R22, iso-butane, R152a, $\mathrm{R} 143 \mathrm{a}$, and butane. But it decreases for iso-pentane and normal pentane. Fig. 7 also shows that the working fluid which has the maximum exergy efficiency varies with turbine inlet pressure.

\section{CONCLUSIONS}

In this paper, the exergetical performance of organic Rankine cycle with internal heat exchanger has been analyzed based on the second law of thermodynamics. The anergy ratio at source heat exchanger or regenerator decreases monotonically with increasing turbine inlet pressure for all fluids. For ammonia, the anergy ratio at heat exchanger is the greatest among the components of the system. However, the anergy ratio at regenerator is the greatest for R143a, while the anergy ratio of exhaust is the greatest for iso-pentane or normal pentane. Exergy efficiency generally increases with turbine inlet pressure for such as ammonia or R134a, but decreases for iso-pentane and normal pentane. For a given source temperature, working fluid which has the maximum exergy efficiency varies with turbine inlet pressure.

\section{ACKNOWLEDGMENT}

This paper was supported by Research Fund, Kumoh National Institute of Technology.

\section{REFERENCES}

[1] N. A. Lai, M. Wendland, and J. Fisher, "Working fluids for high temperature organic Rankine cycle,” Energy, vol. 36, pp. 199-211, 2011.

[2] K. H. Kim, C. H. Han, and K. Kim, "Effects of ammonia concentration on the thermodynamic performances of ammonia-water based power cycles," Thermochimica Acta, vol. 530, pp. 7-16, 2012.

[3] T. C. Hung, T. Y. Shai, and S. K. Wang, "A review of organic Rankine cycles (ORCs) for the recovery of low-grade waste heat," Energy, vol. 22, pp. 661-667, 1997.

[4] U. Drescher and D. Brueggemann, "Fluid selection for the organic Rankine cycle (ORC) in biomass power and heat plants," Applied Thermal Eng., vol. 27, pp. 223-228, 2007.

[5] Y. Dai, J. Wang, and L. Gao, "Parametric optimization and comparative study of organic Rankine cycle (ORC) for low grade waste heat recovery," Energy Convs. Mgmt., vol. 50, pp. 576-582, 2009.

[6] F. Heberle and D. Brueggemann, "Exergy based fluid selection for a geothermal organic Rankine cycle for combined heat and power generation," Applied Thermal Eng., vol. 30, pp. 1326-1332, 2010.

[7] B. F. Tchanche, G. Papadakis, and A. Frangoudakis, "Fluid selection for a low- temperature solar organic Rankine cycle," Applied Thermal Eng., vol. 29, pp. 2468-2476, 2009.

[8] T. C. Hung, S. K. Wang, C. H. Kuo, B. S. Pei, and K. F. Tsai, "A study of organic working fluids on system efficiency of an ORC using low-grade energy sources," Energy, vol. 35, pp. 1403-1411, 2010.

[9] K. H. Kim, "Effects of superheating on thermodynamic performance of organic Rankine cycles,"WASET, vol. 78, pp. 608-612, 2011.

[10] K. H. Kim, "Thermodynamic performance of regenerative organic Rankine cycles," WASET, vol. 59, pp. 1515-1519, 2011.

[11] K. H. Kim and C. H. Han, "Analysis of transcritical organic Rankine cycles for low-grade heat conversion," Adv. Sci. Lett., vol. 8, pp. 216-221, 2012.

[12] K. H. Kim and H. J. Ko, "Exergetical performance assessment of organic Rankine cycle with superheating," App. Mech. Materials, vol. 234, pp. 69-73, 2012. 
[13] T. Yang, G. J. Chen, and T. M. Guo, "Extension of the Wong-Sandler mixing rule to the three-parameter Patel-Teja equation of state: Application up to the near-critical region," Chem. Eng. J., vol. 67, pp. 27-36, 1997.

[14] L. D. Gao, Z. Y. Li, S. G. Zhu, and S. G. Ru, "Vapor-liquid equilibria calculation for asymmetric systems using Patel-Teja equation of state with a new mixing rule, " Fluid Phase Equilibria, vol. 224, pp. 213219, 2004.

[15] C. L. Yaws, Chemical properties handbook, McGraw-Hill, 1999

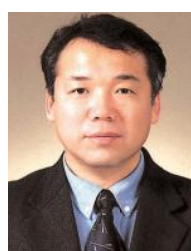

Kyoung Hoon Kim received the Ph.D. degree in mechanical engineering from Korea Advanced Institute of Science and Technology (KAIST). He is currently a Professor in the Department of Mechanical Engineering at Kumoh National Institute of Technology, Korea. His research interests are in the areas of modeling and design of energy systems.

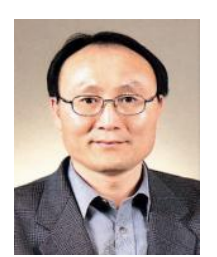

Hyung Jong Ko received the Ph.D. degree in mechanical engineering from Korea Advanced Institute of Science and Technology (KAIST). He is currently a Professor in the Department of Mechanical Engineering at Kumoh National Institute of Technology, Korea. His research interests are in the areas of modeling of simultaneous heat and mass transfer, and analysis of magnetic fluid flow.

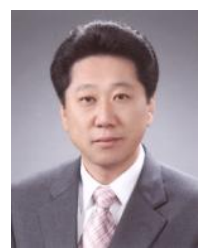

Se Woong Kim received the Ph.D. degree in mechanical engineering from Seoul National University. $\mathrm{He}$ is currently a Professor in the Department of Mechanical Engineering at Kumoh National Institute of Technology, Korea. His research interests are in the areas of automotive engineering and new energy system. 